\title{
Use of human fibrinogen concentrate during proximal aortic reconstruction with deep hypothermic circulatory arrest
}

\author{
Jennifer M. Hanna, MD, MBA, ${ }^{a}$ Jeffrey E. Keenan, MD, ${ }^{a}$ Hanghang Wang, MD, ${ }^{2}$ \\ Nicholas D. Andersen, MD, ${ }^{\mathrm{a}}$ Jeffrey G. Gaca, MD, ${ }^{\mathrm{a}}$ Frederick W. Lombard, MB, ChB, ${ }^{\mathrm{b}}$ \\ Ian J. Welsby, MBBS, FRCA, ${ }^{b}$ and G. Chad Hughes, MD ${ }^{a}$
}

\begin{abstract}
Objective: Human fibrinogen concentrate (HFC) is approved by the Food and Drug Administration for use at $70 \mathrm{mg} / \mathrm{kg}$ to treat congenital afibrinogenemia. We sought to determine whether this dose of HFC increases fibrinogen levels in the setting of high-risk bleeding associated with aortic reconstruction and deep hypothermic circulatory arrest (DHCA).
\end{abstract}

Methods: This was a prospective, pilot, off-label study in which 22 patients undergoing elective proximal aortic reconstruction with DHCA were administered $70 \mathrm{mg} / \mathrm{kg}$ HFC upon separation from cardiopulmonary bypass (CPB). Fibrinogen levels were measured at baseline, just before, and 10 minutes after HFC administration, on skin closure, and the day after surgery. The primary study outcome was the difference in fibrinogen level immediately after separation from CPB, when HFC was administered, and the fibrinogen level 10 minutes following HFC administration. Additionally, postoperative thromboembolic events were assessed as a safety analysis.

Results: The mean baseline fibrinogen level was $317 \pm 49 \mathrm{mg} / \mathrm{dL}$ and fell to $235 \pm 39 \mathrm{mg} / \mathrm{dL}$ just before separation from CPB. After HFC administration, the fibrinogen level rose to $331 \pm 41 \mathrm{mg} / \mathrm{dL}(P<.001)$ and averaged $372 \pm 45 \mathrm{mg} / \mathrm{dL}$ the next day. No postoperative thromboembolic complications occurred.

Conclusions: Administration of $70 \mathrm{mg} / \mathrm{kg}$ HFC upon separation from CPB raises fibrinogen levels by approximately $100 \mathrm{mg} / \mathrm{dL}$ without an apparent increase in thrombotic complications during proximal aortic reconstruction with DHCA. Further prospective study in a larger cohort of patients will be needed to definitively determine the safety and evaluate the efficacy of HFC as a hemostatic adjunct during these procedures. (J Thorac Cardiovasc Surg 2016;151:376-82)

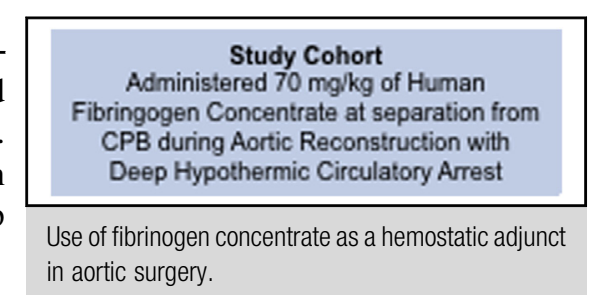

Central Message

Fibrinogen concentrate may be a useful hemostatic adjunct during aortic reconstruction with hypothermic circulatory arrest.

\section{Perspective}

In this prospective, pilot study it is shown that fibrinogen concentrate administered at the FDA-approved dose $(70 \mathrm{mg} / \mathrm{kg})$ increased serum fibrinogen by approximately $100 \mathrm{mg} / \mathrm{dL}$ without an apparent increase in thrombotic complications during proximal aortic reconstruction with DHCA, suggesting fibrinogen concentrate may be a useful adjunct for coagulopathy management during these procedures.

See Editorial Commentary page 383.

See Editorial page 296.
Surgery of the aortic arch with deep hypothermic circulatory arrest (DHCA) is often associated with coagulopathic bleeding as a result of coagulation factor consumption during prolonged periods of cardiopulmonary bypass (CPB) and hypothermia-related platelet dysfunction. ${ }^{1}$ Fibrinogen

From the a Division of Cardiovascular and Thoracic Surgery, Department of Surgery, and ${ }^{b}$ Division of Cardiac Anesthesiology, Department of Anesthesiology, Duke University Medical Center, Durham, NC.

G.C.H. and I.J.W. are both senior authors of this work.

Financial support for this study was received from CSL Behring (Marburg, Germany).

CSL Behring also donated human fibrinogen concentrate for the purposes of conducting this study.

Received for publication April 6, 2015; revisions received Aug 11, 2015; accepted for publication Aug 23, 2015; available ahead of print Sept 28, 2015.

Address for reprints: Ian J. Welsby, MBBS, FRCA, Department of Anesthesiology, Duke University Medical Center, Box 3094, 3409A Hospital N, Durham, NC 27710 (E-mail: ian.welsby@dm.duke.edu).

0022-5223/\$36.00

Copyright (c) 2016 by The American Association for Thoracic Surgery

http://dx.doi.org/10.1016/j.jtcvs.2015.08.079 consumption is particularly exaggerated during these procedures, and the ability to replete fibrinogen represents an important element for the correction of this coagulopathy. Fibrinogen is traditionally replaced by transfusion with plasma or cryoprecipitate. ${ }^{2,3}$ However, in addition to the increased morbidity and mortality risk that results from large volume blood product transfusion, ${ }^{3-5}$ the use of plasma or cryoprecipitate for fibrinogen replacement has several specific disadvantages. ${ }^{6}$ First, the amount of fibrinogen given with plasma or cryoprecipitate transfusion is unknown, prohibiting the ability to replete fibrinogen in a

Scanning this $\mathrm{QR}$ code will take you to the article title page.

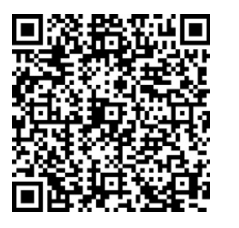




\section{Abbreviations and Acronyms \\ $\mathrm{CPB}=$ cardiopulmonary bypass \\ $\mathrm{DHCA}=$ deep hypothermic circulatory arrest \\ FDA $=$ Food and Drug Administration \\ HFC = human fibrinogen concentrate \\ $\mathrm{PRBC}=$ packed red blood cells}

targeted manner. Second, cryoprecipitate and plasma delivery requires product thawing, which can result in critical delays in the setting of acute operative bleeding. Third, there is no virus inactivation or elimination process for cryoprecipitate, imparting the risk of virus transmission upon transfusion. Lastly, plasma and cryoprecipitate contain alloantigens, which can result in anaphylaxis or less severe hypersensitivity reactions. ${ }^{6}$

For these reasons, human fibrinogen concentrate (HFC) (RiaSTAP; CSL Behring, Marburg, Germany) represents an attractive alternative for the correction of acquired fibrinogen deficiency compared with plasma or cryoprecipitate. HFC is a highly purified, lyophilized, virus-inactivated fibrinogen powder manufactured from human plasma. Current evidence suggests that fibrinogen concentrates are well tolerated and can quickly restore hemostasis in patients with fibrinogen deficiencies. 7,8 Several European reports on the use of HFC for trauma-related massive hemorrhage and acquired perioperative fibrinogen deficiency, including in the setting of cardiothoracic surgery, have also been published previously. ${ }^{9-16}$ However, in the United States, HFC is reserved for replacement therapy in congenital fibrinogen deficiency and reports in the United States testing the efficacy of HFC in correcting acquired fibrinogen deficiency in aortic surgery are lacking. As such, the primary aim of this study was to test the hypothesis that use of HFC at the approved US Food and Drug Administration (FDA) dose of $70 \mathrm{mg} / \mathrm{kg}$ increases fibrinogen levels in the high-risk setting of coagulopathic bleeding of proximal aortic reconstruction with hemiarch replacement after DHCA.

\section{PATIENTS AND METHODS \\ Study Design and Patient Population}

This was a single-center, prospective, pilot, off-label study designed to determine whether HFC increases fibrinogen levels when administered as a 1-time $70 \mathrm{mg} / \mathrm{kg}$ dose upon separation from CPB during nonemergent proximal aorta/hemiarch reconstruction with DHCA. The study protocol was approved by the Duke University Medical Center Institutional Review Board, and informed consent was obtained from each patient who was enrolled. Patients aged $\geq 18$ years undergoing nonemergent proximal thoracic aortic reconstruction (ascending aorta with or without aortic valve or root) with hemiarch replacement and DHCA from December 2010 to April 2012 were eligible for the study. Exclusion criteria were concomitant coronary artery bypass grafting, coronary artery stenting within the past 3 years, refusal of blood transfusion, myocardial infarction within the past 3 months, pregnancy, an international normalized ratio $>1.5$, thienopyridines within 5 days of surgery, aspirin $(325 \mathrm{mg}$ ) within 48 hours of surgery ( $81 \mathrm{mg}$ aspirin was acceptable), platelet count $<100,000 / \mathrm{mm}^{3}$, inability to obtain written informed consent, and known coagulopathy.

\section{Conduct of Surgery}

Surgical techniques and the conduct of operation used for proximal aortic repair and hemiarch replacement were as described previously. ${ }^{17}$ Porcine heparin was administered as a $300 \mathrm{U} / \mathrm{kg}$ bolus and then supplemented to maintain an activated clotting time longer than 480 seconds during CPB. Additionally, a 5000-unit bolus of heparin was given before circulatory arrest. Before the portion of the aortic reconstruction requiring DHCA, the patient was cooled on CPB until electrocerebral inactivity was detected by electroencephalography as described. ${ }^{18,19}$

\section{Transfusion and Coagulopathy Management}

An institutional transfusion algorithm has been developed for the management of bleeding and coagulopathy when separating from CPB in cases of aortic reconstruction with DHCA (Figure 1). This algorithm is based on our previously published experience on transfusion requirements during these procedures ${ }^{1}$ as well as societal perioperative transfusion guidelines. ${ }^{2,3}$ In brief, antifibrinolytic therapy with epsilonaminocaproic acid is administered as a $5-\mathrm{g}$ bolus followed by a $1-\mathrm{g} / \mathrm{h}$ infusion continued in the intensive care unit. Before separation from $\mathrm{CPB}$, upon rewarming and reperfusion, the bypass pump is primed with 4 units plasma. This quantity was selected based on the fact that it represented the 25th percentile plasma requirement after aortic reconstruction with DHCA in our prealgorithm experience. ${ }^{1}$ Also before separation from $\mathrm{CPB}$, hemofiltration is performed to ameliorate coagulation factor dilution, and a set of laboratory test results are obtained to help guide management. Protamine sulfate is then administered until activated clotting time is normalized. At the time of separation from $\mathrm{CPB}$, an additional 5-g bolus of epsilon-aminocaproic acid is given, and a $0.3 \mu \mathrm{g} / \mathrm{kg}$ dose of desmopressin acetate is administered to help correct platelet dysfunction and increase factor VIII and von Willebrand factor levels. If hemostasis is not immediately achieved, 1 unit platelets is transfused followed by a second if bleeding persists. At this point, laboratory results are rechecked, and if bleeding persists an additional unit of platelets and 2 units plasma are administered. Based on laboratory results, cryoprecipitate (if fibrinogen level $<200 \mathrm{mg} / \mathrm{dL}$ ), platelets (if $<100,000 / \mathrm{mm}^{3}$ more than the pre-CPB separation platelet value), and/or 2 plasma units are then transfused. If bleeding continues, recombinant activated factor VII (1-2 mg) is administered. ${ }^{20}$ If hemostasis is still not obtained, packed red blood cells (PRBCs) and plasma are administered at 1:1 with additional cryoprecipate, platelets, and hemostatic adjuncts administered at clinician discretion, with guidance from laboratory and functional tests. With regard to red blood cell transfusion, serial hematocrit samples are drawn before and after separation from CPB. The return of washed, shed red blood cells (BRAT II blood cell salvage machine; Cobe Cardiovascular Inc, Arvada, Colo) to the patient is used in all cases and additional PRBC transfusion is generally avoided if hematocrit is $>0.20$.

In total, although this algorithmic approach for the management of bleeding and coagulopathy after CPB with DHCA is mostly empirical, it was developed to allow the reliable and timely management of the severe coagulopathic bleeding that often occurs in aortic reconstruction with DHCA. Although intraoperative laboratory testing, including thromboelastography and platelet agglutination, are employed when available, our approach is not ultimately reliant on such tests. Although these intraoperative tests can be useful in directing intraoperative transfusion when coming off $\mathrm{CPB},{ }^{21-23}$ they often do not provide information rapidly enough to guide therapy with acute intraoperative bleeding. Therefore, the supplemental information provided by intraoperative laboratory testing is used in conjunction with clinical judgment to modify the protocol when 


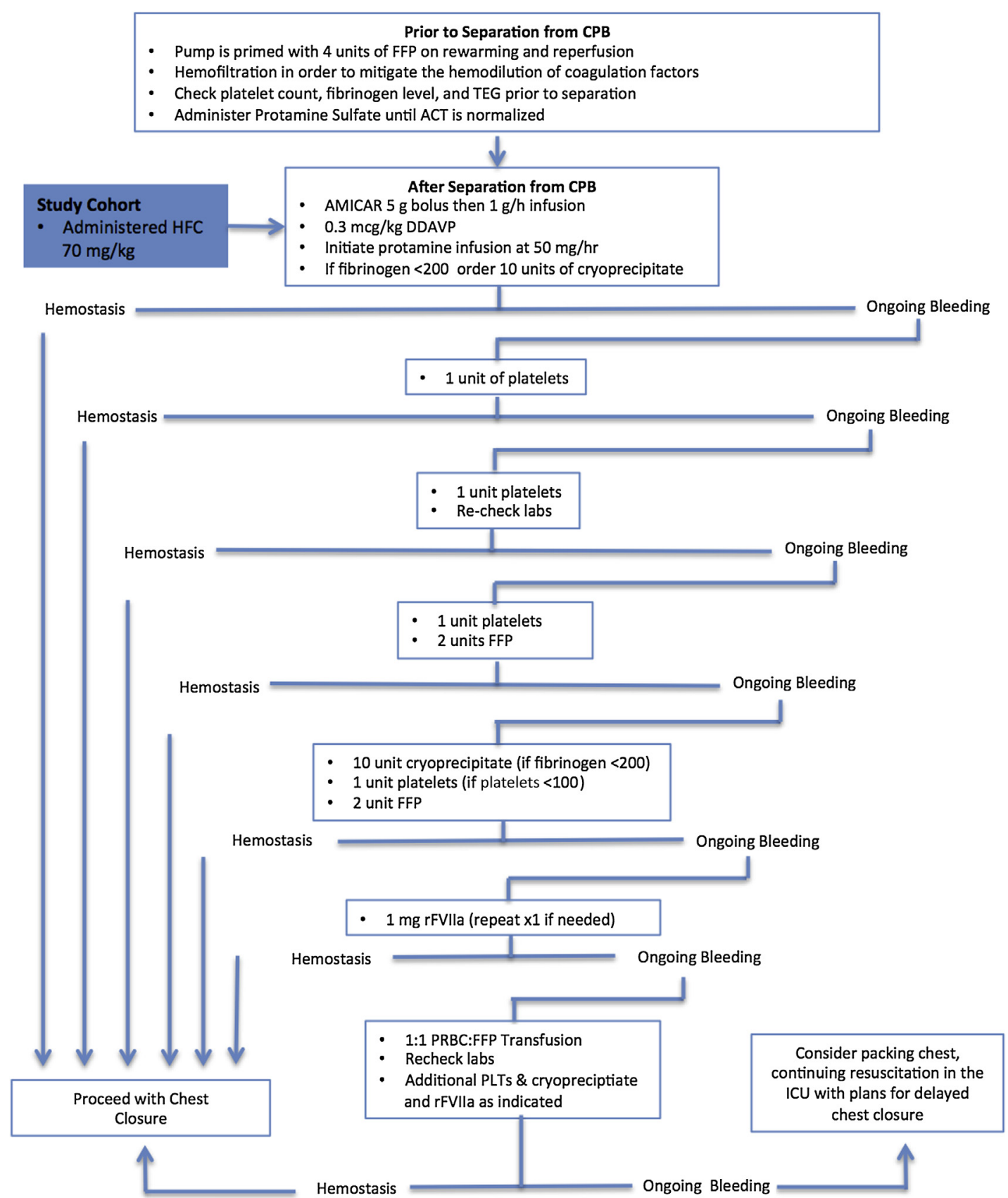

FIGURE 1. Institutional transfusion algorithm schematic. In addition to standard treatment with the transfusion algorithm, the study cohort received $70 \mathrm{mg} /$ kg human fibrinogen concentrate $(H F C)$ upon separation from cardiopulmonary bypass $(C P B)$ (blue shaded box). FFP, Fresh frozen plasma; $T E G$, thromboelastogram; ACT, activated clotting time; AMICAR, epsilon-aminocaproic acid; DDAVP, desmopressin; $r F V I I a$, recombinant activated Factor VII; PRBC, packed red blood cells; $P L T$, single-donor apheresis platelet unit; $I C U$, intensive care unit.

appropriate. After leaving the operating room, practices for postoperative transfusion were carried out according to societal guidelines.,3

\section{HFC Administration and Fibrinogen Level Monitoring}

Patients enrolled in the study were administered $70 \mathrm{mg} / \mathrm{kg}$ HFC at the time of separation from CPB (Figure 1). Fibrinogen levels were measured at 5 time points: baseline at anesthesia induction, after separation from $\mathrm{CPB}$ when protamine was given, 10 minutes following $\mathrm{HFC}$ administration, on admission to the intensive care unit, and 24 hours after anesthesia induction. Fibrinogen activity was determined using a modified Clauss assay (detection limit, $0.2 \mathrm{~g} / \mathrm{L}$ ). In a subset of patients, a whole blood multiplate electroaggregometer (Diapharma, West Chester, Ohio) was used to evaluate platelet aggregation in response to adenosine diphosphate and thrombin receptor activating peptide agonists.

The primary study outcome was the difference in fibrinogen level immediately after separation from CPB, when HFC was administered, and the fibrinogen level 10 minutes following HFC administration. No formal power calculation was performed to determine the number of patients that 
would need to be enrolled to detect a statistically significant difference for a given increase in fibrinogen level. Instead, enrollment in this pilot study was determined largely by practical factors such as funding and personnel resources.

\section{Safety Outcomes}

In addition to our primary outcome, a number of secondary outcomes were assessed to evaluate the safety of HFC and the extent of bleeding and transfusion requirement in these patients. Thromboembolic events and postoperative complications were defined according to Society of Thoracic Surgeons definitions. ${ }^{24}$ The study data safety and monitoring board, composed of a hematologist and transfusion medicine pathologist not otherwise involved in the study, reviewed all inpatient complications and adverse events to determine whether they may have been related to HFC administration. Additionally, bleeding and transfusion data collected included cell saver during and after CPB; intraoperative PRBC, plasma, platelet, and cryoprecipitate requirements before and after separation from CPB; postoperative PRBC, plasma, platelet, and cryoprecipitate requirements through postoperative day 2 ; and chest tube drainage 24 hours postoperatively.

\section{Statistical Analysis}

Fibrinogen levels, laboratory assessments, bleeding, and transfusion data were summarized descriptively. Repeated measures analysis of variance with the Bonferroni adjustment for multiple comparisons was used to test for change in fibrinogen level with time. Statistical analyses were performed with SAS 9.3 (SAS Institute Inc, Cary, NC).

\section{RESULTS}

\section{Study Population}

Twenty-two patients were enrolled and completed the study (Figure 2). Five patients approached for participation in the study did not give consent. An additional patient who was enrolled in the study required coronary artery bypass grafting as part of his procedure and was therefore excluded. In total, the final study cohort represented $23 \%$

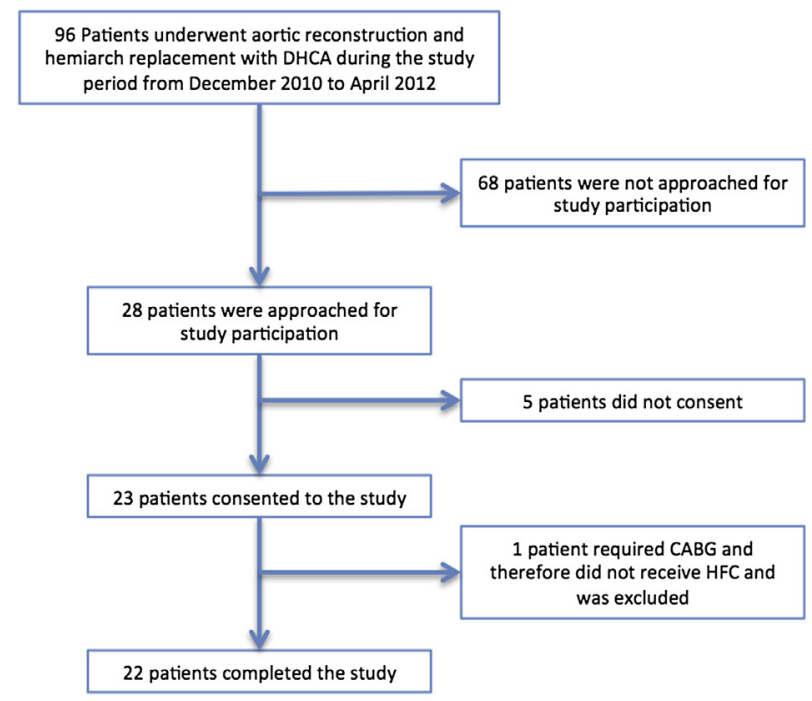

FIGURE 2. Consolidated Standards of Reporting Trials diagram. DHCA, Deep hypothermic circulatory arrest; $C A B G$, coronary artery bypass grafting; $H F C$, human fibrinogen concentrate.
(22 out of 96) of all patients undergoing hemiarch aortic reconstruction with DHCA during the study interval.

Patient and procedural characteristics of the study group are shown in Table 1. The mean age of the study group was $51.9 \pm 13.7$ years. The indication for surgery was predominately aneurysmal disease related to bicuspid aortic valve syndrome $(\mathrm{n}=13 ; 59.1 \%)$ or atherosclerotic aneurysm $(\mathrm{n}=8 ; 36.4 \%)$. Three patients $(13.6 \%)$ underwent redo sternotomy and 9 patients $(40.9 \%)$ required root replacement. Mean operative and CPB times were $310 \pm 44$ minutes and $202 \pm 30$ minutes, respectively. The mean circulatory arrest time was $16.5 \pm 4.1$ minutes. Adjunctive cerebral perfusion was used in all cases with antegrade cerebral perfusion employed in 17 cases $(77.3 \%)$ and retrograde cerebral perfusion used in the remaining 5 cases $(22.7 \%)$. The minimum core (bladder) and nasopharyngeal temperatures in the cohort were $16.7^{\circ} \mathrm{C} \pm 1.5^{\circ} \mathrm{C}$ and $14.7^{\circ} \mathrm{C} \pm 2.0^{\circ} \mathrm{C}$, respectively.

\section{Fibrinogen Activity}

Mean, median, maximum, and minimum fibrinogen plasma activity levels at the measured time points are displayed in Table 2. On average, fibrinogen plasma activity levels decreased from $317 \pm 49 \mathrm{mg} / \mathrm{dL}$ preoperatively to $235 \pm 39 \mathrm{mg} / \mathrm{dL}(26 \% \pm 9 \%)$ at separation from CPB. Ten minutes following the administration of HFC, the mean fibrinogen plasma activity levels increased significantly to a peak of $331 \pm 41 \mathrm{mg} / \mathrm{dL}$, or a mean increase of $97 \pm 33 \mathrm{mg} / \mathrm{dL}(43 \% \pm 17 \%)$. Subsequent to this time point the average fibrinogen level remained approximately at the baseline level or greater.

\section{Safety Outcomes}

There were no thromboembolic complications postoperatively. Thirty-day and in-hospital rates of death, stroke, and renal failure were $0 \%$, and there were no reoperations for bleeding. There were 10 patients $(43 \%)$ who experienced postoperative complications, including focal axillary artery dissection related to axillary arterial cannulation $(\mathrm{n}=1)$, postoperative atrial fibrillation $(\mathrm{n}=6)$, other dysrhythmia $(\mathrm{n}=3)$ (eg, left bundle branch block, transient complete heart block, and atrial flutter), and left recurrent laryngeal nerve palsy $(n=2)$. None of these complications were deemed related to the administration of HFC. There was 1 30-day readmission in the cohort for atrial flutter, which was also unrelated to HFC administration.

\section{Laboratory Assessment, Bleeding, and Transfusion}

The mean and median hematocrit levels were highest at baseline ( $42 \%$ and $43 \%$, respectively) (Table 2 ). After an initial decrement due to intraoperative blood loss, hematocrit remained stable from the initial postoperative value through postoperative day 1 . Following separation from CPB (during and immediately after administration of 
TABLE 1. Patient and procedural characteristics of the study cohort $(\mathbf{n}=\mathbf{2 2})$

\begin{tabular}{|c|c|}
\hline Variable & Result \\
\hline Age (y) & $51.9 \pm 13.7$ \\
\hline Male & $15(68.2)$ \\
\hline White race & $18(81.8)$ \\
\hline Body mass index & $29.9 \pm 6.6$ \\
\hline Hypertension & $16(72.7)$ \\
\hline Hyperlipidemia & $13(59.1)$ \\
\hline Smoker & $12(54.5)$ \\
\hline Diabetes & $2(9.1)$ \\
\hline Coronary artery disease & $6(27.3)$ \\
\hline History of stroke/transient ischemic attack & $2(9.1)$ \\
\hline Chronic obstructive pulmonary disease & $1(4.5)$ \\
\hline Renal insufficiency* & $1(4.5)$ \\
\hline Peripheral vascular disease & $0(0)$ \\
\hline Redo sternotomy & $3(13.6)$ \\
\hline Root replacement & $9(40.9)$ \\
\hline Ascending aortic repair & $12(54.5)$ \\
\hline Concomitant procedure & $5(22.7)$ \\
\hline Previous aortic surgery & $3(13.6)$ \\
\hline Atherosclerotic disease & $8(36.4)$ \\
\hline Bicuspid aortic valve syndrome & $13(59.1)$ \\
\hline Chronic type a dissection & $1(4.5)$ \\
\hline Previous aortic dissection & $2(9.1)$ \\
\hline Presenting aortic symptoms & $2(9.1)$ \\
\hline Ejection fraction $(\%)$ & $54.3 \pm 1.8$ \\
\hline Aortic insufficiency & $10(45.5)$ \\
\hline Max aortic diameter $(\mathrm{cm})$ & $5.6 \pm 0.7$ \\
\hline \multicolumn{2}{|l|}{ American Society of Anesthesiologists class } \\
\hline 2 & $1(4.5)$ \\
\hline 3 & $21(95.5)$ \\
\hline Retrograde cerebral perfusion & $5(22.7)$ \\
\hline Antegrade cerebral perfusion & $17(77.3)$ \\
\hline Minimum core temperature $\left({ }^{\circ} \mathrm{C}\right)$ & $16.7 \pm 1.5$ \\
\hline Minimum nasopharyngeal temperature $\left({ }^{\circ} \mathrm{C}\right)$ & $14.7 \pm 2.0$ \\
\hline Operative time (min) & $310 \pm 44.1$ \\
\hline Cardiopulmonary bypass time (min) & $202.1 \pm 30.1$ \\
\hline Circulatory arrest time (min) & $16.5 \pm 4.1$ \\
\hline
\end{tabular}

Baseline and operative characteristics of the human fibrinogen concentrate study cohort and a contemporary cohort without human fibrinogen concentrate undergoing elective proximal aortic surgery, including hemiarch replacement with deep hypothermic circulatory arrest before and after propensity matching. Values are presented as mean \pm standard deviation or $\mathrm{n}(\%)$. *Defined as creatinine level $>1.5 \mathrm{mg} / \mathrm{dL}$.

HFC) a large but highly variable volume of blood was processed through the cell saver as evidenced by a median of $505 \mathrm{~mL}$ cell saver product (interquartile range [IQR], 242-725 mL cell saver product) being reinfused (Table 3). Generally, subjective evaluation of the surgical field by the attending surgeon following separation from CPB and HFC administration indicated persistence of microvascular bleeding, as evidenced by lack of visible clot and absence of surgically correctable bleeding sites. Additionally, more than $90 \%$ of the cohort required platelet transfusion (median, 2 units [IQR, 2-3 units]) after separation from CPB to achieve resolution of microvascular bleeding. This was in the setting of a more than $50 \%$ decrease in adenosine diphosphate-stimulated platelet aggregation (within our locally determined range for clopidogrel maintenance therapy) in a subset of 9 patients where multiplate electroaggregometer data were available.

Consistent with our algorithmic approach toward the management of coagulopathy and bleeding during these procedures, the bypass pump was primed with 4 units fresh frozen plasma immediately before separation in 17 cases $(77.3 \%)$. Additionally, 7 patients $(31.8 \%)$ received plasma following separation from CPB with a median transfusion of 2 units (IQR, 1-4 units). Only 3 patients (13.6\%) required intraoperative cryoprecipitate transfusion, all following separation from CPB. A total of 9 patients $(40.9 \%)$ required PRBC transfusion following separation from CPB. Additionally, 6 patients required PRBC transfusion during the early postoperative period, whereas transfusion of other blood product types was minimal postoperatively. The median 24-hour chest tube output postoperatively was $525 \mathrm{~mL}$ (IQR, 338-720 mL).

\section{DISCUSSION}

Here we present the first prospective study on the use of $\mathrm{HFC}$ as a hemostatic adjunct during aortic surgery in the United States. When HFC was administered at the FDAapproved dose of $70 \mathrm{mg} / \mathrm{kg}$ at the time of separation from CPB after aortic reconstruction with DHCA we found that fibrinogen levels increased by approximately $100 \mathrm{mg} / \mathrm{dL}$ within 10 minutes. Additionally, there were no adverse events related to the administration of HFC observed in the study cohort. Thus, the findings from this pilot study suggest that HFC may safely and rapidly raise fibrinogen levels in the high-risk setting for coagulopathic bleeding associated with aortic reconstruction and DHCA.

By rapidly restoring fibrinogen levels during these procedures HFC may offer several advantages over conventional methods for fibrinogen repletion (eg, transfusion of plasma and cryoprecipitate). First, administration of HFC may be time-saving by precluding the need for thawing and crossmatching. Second, because the dose of fibrinogen in HFC is known, it can be given in an intelligible fashion to raise fibrinogen values to a targeted level, which is not the case with the administration of plasma or cryoprecipitate. Finally, administration of HFC avoids some of the risks associated with allogeneic blood product transfusion, including infectious disease transmission, hypersensitivity reactions, and adverse events related to volume overload and other issues that arise with large volume blood product transfusion. ${ }^{3-5,25-27}$

Despite the potential benefit that HFC may hold as a hemostatic adjunct during aortic surgery with DHCA, it was also clear from this study that HFC does not completely reverse the coagulopathy incurred with these procedures. This was evidenced by the considerable platelet transfusion 
TABLE 2. Fibrinogen plasma activity levels and hematocrit at specified time points

\begin{tabular}{|c|c|c|c|c|c|}
\hline \multirow[b]{2}{*}{ Variable } & \multicolumn{5}{|c|}{ Time point* } \\
\hline & $\mathbf{A}$ & B & $\mathbf{C}$ & D & $\mathbf{E}$ \\
\hline \multicolumn{6}{|l|}{ Fibrinogen activity level (mg/dL) } \\
\hline Mean \pm standard deviation & $317 \pm 49$ & $235 \pm 39 \dagger$ & $331 \pm 41$ & $312 \pm 41$ & $372 \pm 45$ \\
\hline Median (interquartile range) & $301(280-341)$ & $224(217-256)$ & $337(302-363)$ & $311(291-333)$ & $357(343-388)$ \\
\hline Maximum & 414 & 345 & 404 & 382 & 480 \\
\hline Minimum & 255 & 154 & 257 & 210 & 316 \\
\hline \multicolumn{6}{|l|}{ Hematocrit (\%) } \\
\hline Mean \pm standard deviation & $42 \pm 6$ & $28 \pm 5$ & $28 \pm 4$ & $28 \pm 2$ & $30 \pm 3$ \\
\hline Median (interquartile range) & $43(40-45)$ & $27(24-32)$ & $27(26-31)$ & $29(27-30)$ & $31(28-32)$ \\
\hline Maximum & 50 & 37 & 38 & 34 & 34 \\
\hline Minimum & 25 & 20 & 21 & 23 & 25 \\
\hline
\end{tabular}

*A = baseline at anesthesia induction; $\mathrm{B}=$ after separation from $\mathrm{CPB}$ when protamine is given; $\mathrm{C}=10$ minutes following human fibrinogen concentrate administration; $\mathrm{D}=$ on admission to the intensive care unit; and $\mathrm{E}=24$ hours after anesthesia induction. $†$ Significantly different value by analysis of variance with Bonferroni correction for multiple comparisons $(P<.0001)$.

requirement and microvascular bleeding observed after separation from $\mathrm{CPB}$ in patients who had received HFC, as well as the severe platelet dysfunction demonstrated in the subset of patients who had platelet aggregometry data. This suggests that platelet dysfunction, which is a well-known occurrence after DHCA, ${ }^{28}$ was a major contributing factor to the persistent coagulopathy observed in the patients who had received HFC, indicating that adjunctive HFC may not address this aspect of coagulopathy after aortic reconstruction with hypothermia.

Although this is the first prospective study on HFC conducted in the United States, several pilot studies from European centers have evaluated HFC in aortic and cardiac surgery previously. Rahe-Mayer and colleagues ${ }^{14}$ found that administration of HFC resulted in reduced postoperative bleeding and allogeneic transfusion, including

TABLE 3. Transfusion at specified time points in the study cohort $(\mathbf{n}=\mathbf{2 2})$

\begin{tabular}{lccc}
\hline \multicolumn{1}{c}{ Variable } & During CPB & After CPB* & Postoperative \\
\hline Cell saver $(\mathrm{mL})$ & $178(18-303)$ & $505(242-725)$ & - \\
Packed red blood cells & & & \\
$\quad$ Underwent transfusion & $2(9.1)$ & $9(40.9)$ & $6(27.3)$ \\
$\quad$ Units & $1.5(1-2)$ & $1(1-2)$ & $1(1-2)$ \\
Fresh frozen plasma & & & \\
$\quad$ Underwent transfusion & $17(77.3)$ & $7(31.8)$ & $1(4.5)$ \\
$\quad$ Units & $4(4-4)$ & $2(1-4)$ & 5 \\
Platelets & & & \\
$\quad$ Underwent transfusion & $4(18.2)$ & $20(90.9)$ & $1(4.5)$ \\
$\quad$ Units & $1.5(1-2)$ & $2(1-2)$ & 1 \\
Cryoprecipitate & & & \\
$\quad$ Underwent transfusion & $0(0)$ & $3(13.6)$ & $0(0)$ \\
$\quad$ Units & & $1(1-2)$ & \\
Factor VIIa & $0(0)$ & $2(9.1)$ & $0(0)$ \\
$\quad$ administration & & & \\
\hline
\end{tabular}

Values are presented as median (interquartile range) or $\mathrm{n}(\%) . C P B$, Cardiopulmonary bypass. *After CPB includes before, during, and after administration of HFC until the end of surgery. $\nmid$ Postoperative includes from end surgery through postoperative day 2 . platelets, for patients undergoing ascending aorta replacement and aortic valve surgery with moderate hypothermia $(n=15)$. In addition, Solomon and colleagues ${ }^{29}$ evaluated the effect of HFC in coronary artery bypass grafting and observed a reduction in PRBC transfusion. Because it was a pilot study, the present trial lacked a comparison group to determine whether HFC provided benefit in regard to clinical meaningful end points such as the extent of intraand postoperative blood loss and transfusion requirements. Nevertheless, the rapid fibrinogen repletion without apparent adverse consequences by HFC administration at the FDA-approved dose demonstrated in this study, coupled with the promising findings previously reported by RaheMayer and colleagues ${ }^{14}$ and Solomon and colleagues ${ }^{29}$ should provide a strong basis for future larger-scale prospective evaluation of HFC efficacy as a hemostatic adjunct in aortic and cardiac surgery.

This study has several additional limitations that should be considered. The multifaceted nature of our algorithmic approach toward the management of intraoperative bleeding and coagulopathy makes it difficult to delineate the influence of any single intervention, because variations in the approach to bleeding and coagulopathy management are dictated by case-specific factors. Carefully controlling for such variations will be important considerations for future prospective evaluation of HFC efficacy. We also did not have robust data on intraoperative coagulopathy assessment, which will be important in future studies to objectively determine the extent to which HFC administration improves coagulation system function and clot strength. Finally, although we did not observe any thromboembolic events associated with the administration of HFC, the small sample size of this study leaves a high chance for type II error in regard to safety outcomes. In total, definitive conclusions on the safety and efficacy of HFC should not be drawn from this pilot study. Larger, prospective studies will be needed to firmly establish the safety of HFC and to 
determine whether it is efficacious in the management of coagulopathy during aortic reconstruction with DHCA.

\section{CONCLUSIONS}

We conclude that, when administered at the FDAapproved dose of $70 \mathrm{mg} / \mathrm{kg}$ at the time of separation from $\mathrm{CPB}, \mathrm{HFC}$ rapidly increases fibrinogen levels by approximately $100 \mathrm{mg} / \mathrm{dL}$ and therefore may be a valuable hemostatic adjunct for the correction of coagulopathy associated with aortic reconstruction and DHCA. Further prospective study in a larger cohort of patients will be needed to verify these results and to definitively determine the safety and efficacy of HFC.

\section{Conflict of Interest Statement}

I.J.W. serves as a consultant for CSL Behring. All authors had full freedom of investigation before, during, and after the study in regard to control of the design of the study, acquisition, analysis, and interpretation of data, and freedom to fully disclose all results. All other authors have nothing to disclose with regard to commercial support.

\section{References}

1. Williams JB, Phillips-Bute B, Bhattacharya SD, Shah AA, Andersen ND, Altintas B, et al. Predictors of massive transfusion with thoracic aortic procedures involving deep hypothermic circulatory arrest. J Thorac Cardiovasc Surg. 2011;141:1283-8.

2. Practice guidelines for perioperative blood transfusion and adjuvant therapies: an updated report by the American Society of Anesthesiologists Task Force on Perioperative Blood Transfusion and Adjuvant Therapies. Anesthesiology. 2006;105: 198-208.

3. Ferraris VA, Brown JR, Despotis GJ, Hammon JW, Reece TB, Saha SP, et al. 2011 update to the Society of Thoracic Surgeons and the Society of Cardiovascular Anesthesiologists blood conservation clinical practice guidelines. Ann Thorac Surg. 2011;91:944-82.

4. Engoren MC, Habib RH, Zacharias A, Schwann TA, Riordan CJ, Durham SJ. Effect of blood transfusion on long-term survival after cardiac operation. Ann Thorac Surg. 2002;74:1180-6.

5. Koch CG, Li L, Sessler DI, Figueroa P, Hoeltge GA, Mihaljevic T, et al. Duration of red-cell storage and complications after cardiac surgery. N Engl J Med. 2008; 358:1229-39.

6. Callum JPP. Adverse reactions. In: Clinical Guide to Transfusion. 4th ed. Ottawa: Canadian Blood Services; 2007:82-111.

7. Groner A. Reply to Pereira A. Cryoprecipitate versus commercial fibrinogen concentrate in patients who occasionally require a therapeutic supply of fibrinogen: risk comparison in the case of an emerging transfusion-transmitted infection. Haematologica. 2007;92:846-9. Haematologica. 2008;93:e24-6. author reply e7.

8. Kreuz W, Meili E, Peter-Salonen K, Haertel S, Devay J, Krzensk U, et al. Efficacy and tolerability of a pasteurised human fibrinogen concentrate in patients with congenital fibrinogen deficiency. Transfus Apher Sci. 2005;32:247-53.

9. Danes AF, Cuenca LG, Bueno SR, Mendarte Barrenechea L, Ronsano JB. Efficacy and tolerability of human fibrinogen concentrate administration to patients with acquired fibrinogen deficiency and active or in high-risk severe bleeding. Vox Sang. 2008;94:221-6.

10. Fenger-Eriksen C, Jensen TM, Kristensen BS, Jensen KM, Tonnesen E, Ingerslev J, et al. Fibrinogen substitution improves whole blood clot firmness after dilution with hydroxyethyl starch in bleeding patients undergoing radical cystectomy: a randomized, placebo-controlled clinical trial. J Thromb Haemost. 2009; 7:795-802.

11. Fenger-Eriksen C, Lindberg-Larsen M, Christensen AQ, Ingerslev J, Sorensen B. Fibrinogen concentrate substitution therapy in patients with massive haemorrhage and low plasma fibrinogen concentrations. Br J Anaesth. 2008; 101:769-73.

12. Karlsson M, Ternstrom L, Hyllner M, Baghaei F, Flinck A, Skrtic S, et al. Prophylactic fibrinogen infusion reduces bleeding after coronary artery bypass surgery. A prospective randomised pilot study. Thromb Haemost. 2009;102: $137-44$.

13. Mittermayr M, Streif W, Haas T, Fries D, Velik-Salchner C, Klingler A, et al. Hemostatic changes after crystalloid or colloid fluid administration during major orthopedic surgery: the role of fibrinogen administration. Anesth Analg. 2007; 105:905-17.

14. Rahe-Meyer N, Pichlmaier M, Haverich A, Solomon C, Winterhalter M, Piepenbrock S, et al. Bleeding management with fibrinogen concentrate targeting a high-normal plasma fibrinogen level: a pilot study. Br J Anaesth. 2009;102: 785-92.

15. Rahe-Meyer N, Solomon C, Winterhalter M, Piepenbrock S, Tanaka K, Haverich A, et al. Thromboelastometry-guided administration of fibrinogen concentrate for the treatment of excessive intraoperative bleeding in thoracoabdominal aortic aneurysm surgery. J Thorac Cardiovasc Surg. 2009; 138:694-702.

16. Solomon C, Pichlmaier U, Schoechl H, Hagl C, Raymondos K, Scheinichen D, et al. Recovery of fibrinogen after administration of fibrinogen concentrate to patients with severe bleeding after cardiopulmonary bypass surgery. Br J Anaesth. 2010; 104:555-62.

17. Lima B, Williams JB, Bhattacharya SD, Shah AA, Andersen N, Gaca JG, et al. Results of proximal arch replacement using deep hypothermia for circulatory arrest: is moderate hypothermia really justifiable? Am Surg. 2011;77:1438-44.

18. Husain AM AK, Hughes GC. Thoracic aortic surgery. In: Husain AM, ed. A prac tical approach to neurophysiologic intraoperative monitoring. New York: Demos Medical Publishing; 2008.

19. James ML, Andersen ND, Swaminathan M, Phillips-Bute B, Hanna JM, Smigla GR, et al. Predictors of electrocerebral inactivity with deep hypothermia. J Thorac Cardiovasc Surg. 2014;147:1002-7.

20. Andersen ND, Bhattacharya SD, Williams JB, Fosbol EL, Lockhart EL, Patel MB, et al. Intraoperative use of low-dose recombinant activated factor VII during thoracic aortic operations. Ann Thorac Surg. 2012;93:1921-8; discussion 8-9.

21. Essell JH, Martin TJ, Salinas J, Thompson JM, Smith VC. Comparison of thromboelastography to bleeding time and standard coagulation tests in patients after cardiopulmonary bypass. J Cardiothorac Vasc Anesth. 1993;7:410-5.

22. Despotis GJ, Santoro SA, Spitznagel E, Kater KM, Cox JL, Barnes P, et al. Prospective evaluation and clinical utility of on-site monitoring of coagulation in patients undergoing cardiac operation. J Thorac Cardiovasc Surg. 1994;107:271-9.

23. Nuttall GA, Oliver WC, Ereth MH, Santrach PJ. Coagulation tests predict bleeding after cardiopulmonary bypass. J Cardiothorac Vasc Anesth. 1997;11: 815-23.

24. The Society of Thoracic Surgeons. Adult cardiac surgery data collection. Available at: http://www.sts.org/sts-national-database/database-managers/adult-cardiac-sur gery-database/data-collection. Accessed October 26, 2014.

25. Spiess BD, Royston D, Levy JH, Fitch J, Dietrich W, Body S, et al. Platelet transfusions during coronary artery bypass graft surgery are associated with serious adverse outcomes. Transfusion. 2004;44:1143-8.

26. Stanworth SJ, Brunskill SJ, Hyde CJ, McClelland DB, Murphy MF. Is fresh frozen plasma clinically effective? A systematic review of randomized controlled trials. Br J Haematol. 2004;126:139-52.

27. Vamvakas EC, Carven JH. RBC transfusion and postoperative length of stay in the hospital or the intensive care unit among patients undergoing coronary artery bypass graft surgery: the effects of confounding factors. Transfusion. 2000;40: $832-9$.

28. Thomas R, Hessel EA II, Harker LA, Sands MP, Dillard DH. Platelet function during and after deep surface hypothermia. J Surg Res. 1981;31:314-8.

29. Solomon C, Schochl H, Hanke A, Calatzis A, Hagl C, Tanaka K, et al. Haemostatic therapy in coronary artery bypass graft patients with decreased platelet function: comparison of fibrinogen concentrate with allogeneic blood products. Scand J Clin Lab Invest. 2012;72:121-8.

Key Words: bleeding, blood transfusion, blood coagulation, anesthesia, aortic reconstruction, deep hypothermia, circulatory arrest, fibrinogen, coagulopathy 